\title{
Analysis and flow behaviour prediction of paste material in sheet flow
}

\author{
P.T. Slatter ATC Williams Pty Ltd, Australia
}

\begin{abstract}
The free surface flow behaviour and characterisation of paste and thickened tailings material is of critical importance at discharge. A previous study has shown that these flows can be scaled for engineering design purposes using a sheet flow diagram. The objective of this paper is to develop and evaluate the free surface sheet flow approach for the flow behaviour analyses, rheological characterisation, and prediction of the laminar/turbulent transition for viscoplastic sheet flows of paste and thickened tailings material. The previously developed approach for power law fluids has now been extended to the analysis and flow behaviour prediction of paste and thickened tailings viscoplastic materials. The approach is validated against experimental viscoplastic data, and found to have significant merit in this case. Issues requiring further work have been identified and discussed.
\end{abstract}

\section{Introduction}

The free surface flow behaviour and characterisation of paste and thickened tailings material is of critical importance at discharge. Previous studies have shown that a sheet flow diagram can be constructed, and that these flows can be scaled for engineering design purposes in a manner similar to the approach of Metzner and Reed for tube flow. However, many unresolved issues remain for the rheometrical measurement and flow behaviour analyses of paste and thickened tailings material in free surface sheet flow. Arguably, the most acute of these are the application to viscoplastic paste material and the role that the yield stress may play in the concomitant location of the laminar/turbulent transition region.

The objective of this paper is to develop and evaluate the free surface sheet flow approach for the flow behaviour analyses, rheological characterisation, and prediction of the laminar/turbulent transition for viscoplastic sheet flows of paste and thickened tailings material. The previously developed approach (Slatter et al., 2010), which was shown to be successful for power law fluids (Slatter et al., 2011), should now be extended to the analysis and flow behaviour prediction of paste and thickened tailings viscoplastic materials. Furthermore, the approach should be validated against experimental viscoplastic data, and these form the objectives of this study.

\section{Theory and literature}

The fundamental theory relevant to this paper has been presented by Slatter et al. (2011). The shear stress $\tau$ for sheet flow increases linearly with depth $h$, from zero at the free surface to the wall shear stress $\tau_{0}$ at depth $H$ as indicated in Figure 1. The shear stress distribution is:

$$
\tau=\rho g h \sin \alpha
$$

Where:

$$
\begin{aligned}
\tau & =\text { the shear stress at depth } h(\mathrm{~Pa}) . \\
\rho & =\text { the fluid density }\left(\mathrm{kg} / \mathrm{m}^{3}\right) . \\
g & =\text { gravitational acceleration }\left(\mathrm{m} / \mathrm{s}^{2}\right) . \\
h & =\text { the depth }(\mathrm{m}) . \\
\alpha & =\text { inclination (degrees). }
\end{aligned}
$$


The shear stress distribution is shown in Figure 1.

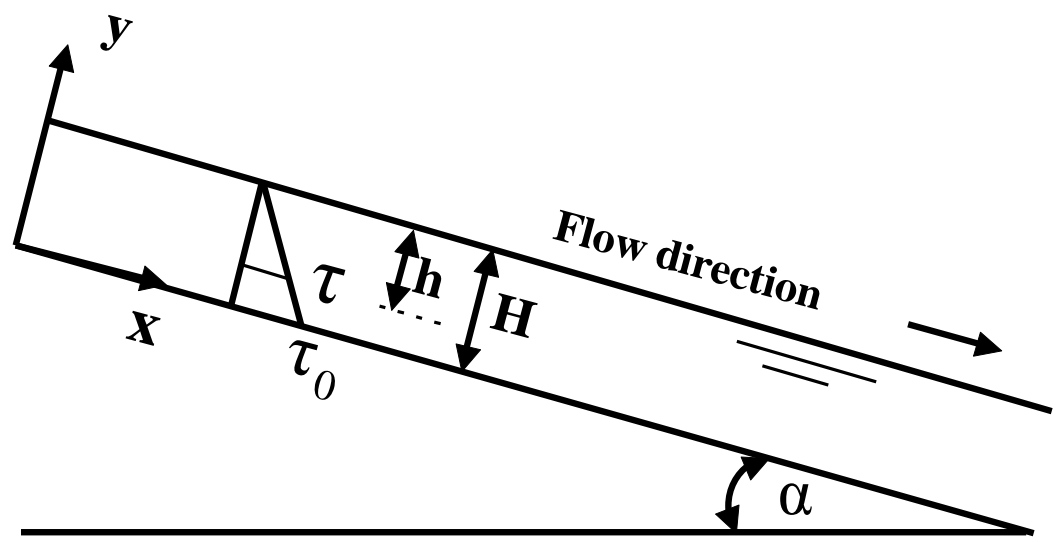

Figure 1 Shear stress distribution for sheet flow (Chow, 1959)

The equation for laminar Newtonian sheet flow is obtained by integrating Equation (1) over the flow depth (Chow, 1959):

$$
Q=\frac{H^{2} \tau_{0}}{3 \mu}
$$

Where:

$Q=$ volumetric flow rate per unit channel width $\left(\mathrm{m}^{3} / \mathrm{s} / \mathrm{m}\right)$.

$H=$ fluid height $(\mathrm{m})$.

$\tau_{o}=$ wall shear stress $(\mathrm{Pa})$.

$\mu=$ dynamic viscosity (Pa.s).

In terms of the mean velocity $V$ :

$$
V=\frac{Q}{H}=\frac{H \tau_{0}}{3 \mu}
$$

Where:

$$
V=\text { mean velocity }(\mathrm{m} / \mathrm{s}) .
$$

For a Newtonian fluid the shear rheology relationship is:

$$
\mu=\frac{\tau}{\mu} \text { and } \quad \& \text { \& }=\frac{\tau_{0}}{\mu}
$$

Where:

$$
\begin{aligned}
& \gamma=\text { the shear rate }\left(\mathrm{s}^{-1}\right) . \\
& \gamma_{0}=\text { the wall shear rate }\left(\mathrm{s}^{-1}\right) .
\end{aligned}
$$

If Equations ( 3 ) and (4) are combined and if this is expressed in terms of the wall shear stress and the wall shear rate the relationship is as follows:

$$
\tau_{0}=\mu \frac{3 V}{H}=\mu \propto \&
$$

Therefore: 


$$
\text { \& }=\frac{3 V}{H}
$$

which gives us the bulk sheet flow shear rate for sheet flow as $3 \mathrm{~V} / \mathrm{H}$.

The wall shear stress for sheet flow is:

$$
\tau_{0}=\rho g H \sin \alpha
$$

Laminar sheet flow can therefore be represented and analysed as a unique relationship between wall shear stress $\tau_{o}$ and bulk shear rate $3 \mathrm{~V} / \mathrm{H}$, as is customarily done for pipe flow.

The sheet flow analysis for a general time independent non-Newtonian fluid can be obtained (Slatter et al., 2010) in terms of the bulk shear rate as:

$$
\left.\frac{3 V}{H}=\frac{3}{\tau_{0}^{2}} \int_{0}^{\tau_{0}} \tau\right) \&(\tau) d \tau
$$

By analogy with tube flow, one can introduce the apparent sheet flow behaviour index $n_{*}^{\prime}$ defined as the slope of the logarithmic plot of wall shear stress $\tau_{o}$ versus bulk shear rate $3 \mathrm{~V} / \mathrm{H}$ (Slatter et al., 2010). Finally, the shear rate at the wall is expressed in terms of the bulk shear rate $(3 \mathrm{~V} / \mathrm{H})$ as (Slatter et al., 2010):

$$
\nLeftarrow=\frac{3 V}{H}\left(\frac{2 n_{*}^{\prime}+1}{3 n_{*}^{\prime}}\right)
$$

Table 1 summarises the analogy of the proposed sheet flow analysis with that of Rabinowitsch and Mooney for tube flow.

Table 1 Comparison of key elements of the rheometric analysis of tube to sheet flow (Slatter et al., 2010)

\begin{tabular}{cccc}
\hline & Bulk shear rate & Wall shear stress & R-M Factor \\
\hline Tube flow & $\frac{8 V}{D}$ & $\frac{D \Delta p}{4 L}$ & $\frac{3 n^{\prime}+1}{4 n^{\prime}}$ \\
Sheet flow & $\frac{3 V}{H}$ & $\rho g H \sin \alpha$ & $\frac{2 n_{*}^{\prime}+1}{3 n_{*}^{\prime}}$
\end{tabular}

This approach can be taken further (Slatter et al., 2010) particularly for power law materials. The apparent sheet flow behaviour index $n_{*}^{\prime}$ has been defined in terms of a power law relationship between the wall shear stress $\tau_{o}$ and the bulk shear rate $3 V / H$. After the method of Metzner and Reed (1955), we can define an apparent sheet flow fluid consistency index $K_{*}^{\prime}$ as:

$$
K_{*}{ }^{\prime}=\frac{\tau_{0}}{\left(\frac{3 V}{H}\right)^{n_{*}}} .
$$

This leads to the fundamentally important laminar flow design equation for sheet flow as:

$$
\tau_{0}=K_{*}{ }^{\prime}\left(\frac{3 V}{H}\right)^{n_{*}{ }^{\prime}} .
$$

In order to accommodate the reality that actual channels may approach sheet flow, but will always have side edges at some point, we replace $H$ with the hydraulic radius $R_{h}$ so that: 


$$
\tau_{0}=K *^{\prime}\left(\frac{3 V}{R_{h}}\right)^{n_{*}{ }^{\prime}}
$$

We can now define a new Reynolds number for sheet flow after the Newtonian paradigm:

$$
\operatorname{Re}_{4}=\frac{8 \rho V^{2}}{\tau_{0}} \text {. }
$$

Combining Equations (12) and (13) we have:

$$
\operatorname{Re}_{4}=\frac{8 \rho V^{2}}{K *^{\prime}\left(\frac{3 V}{R_{h}}\right)^{n_{*}{ }^{\prime}}} .
$$

Slatter et al. (2011) have suggested that this Reynolds number will provide a basis for the establishment of dynamic similarity for sheet flow. In particular, this new Reynolds number should provide a basis for the discrimination between laminar and turbulent flow. They have shown that for a CMC Power Law Fluid that the transitions occurs at a value of $\mathrm{Re}_{4}=700$, and furthermore propose that this be used as the transition criterion for sheet flow. The extension of these concepts to a viscoplastic paste material now forms the objective of this present paper.

\section{Extension to viscoplastic paste material}

For viscoplastic paste material, the Herschel-Bulkley constitutive relationship is appropriate.

$$
\tau=\tau_{y}+K \not \&
$$

Where:

$$
\begin{aligned}
\tau_{y} & =\text { the yield stress }(\mathrm{Pa}) . \\
K & =\text { the fluid consistency index }\left(\mathrm{Pa} . \mathrm{s}^{\mathrm{n}}\right) . \\
n & =\text { the flow behaviour index. }
\end{aligned}
$$

The bulk shear rate $3 \mathrm{~V} / \mathrm{H}$ for Herschel-Bulkley sheet flow can be expressed as

$$
\frac{3 V}{H}=\frac{3 n K}{\tau_{0}(2 n+1)}\left(\frac{\tau_{0}}{K}\right)^{\left(\frac{n+1}{n}\right)}\left(1-\frac{\tau_{y}}{\tau_{0}}\right)^{\left(\frac{n+1}{n}\right)}\left(1+\left(\frac{n}{n+1}\right) \frac{\tau_{y}}{\tau_{0}}\right) .
$$

This follows directly from combining Equations 8 and 15 and the work of De Kee et al (1990).

Since Equation 16 will not yield constant values for the apparent sheet flow behaviour index $n_{*}^{\prime}$ and the apparent sheet flow fluid consistency index $K_{*}^{\prime}$ required to solve for the Reynolds number $R e_{4}$, the sheet flow behaviour rheological parameters will need to be evaluated at each requisite $\tau_{o}$ value required to solve Equation 16. This is in line with the approach originally suggested by Metzner and Reed (1955).

\section{$4 \quad$ Experimental procedure and results}

The experimental work was conducted by the Flow Process Research Centre at the Cape Peninsula University of Technology in a $10 \mathrm{~m}$ long tilting flume which is $300 \mathrm{~mm}$ wide with slopes from 1 to 5 degrees. The maximum flow rate achieved by the progressive cavity positive displacement pump is $24 \mathrm{~L} / \mathrm{s}$ but higher flow rates up to $45 \mathrm{~L} / \mathrm{s}$ were achieved using a centrifugal pump. The flow heights in the channel were measured using digital depth gauges that were linked to the computer but had to be lowered manually to the surface of the fluid in the flume. 
The rheology of the fluids was measured in a tube viscometer with three tubes $(13,28$ and $80 \mathrm{~mm}$ diameter respectively) which is in-line with the tilting flume. Magnetic flow meters and differential pressure transducers are fitted to each line for measuring flow rates and pressure drops. A mass flow meter is fitted to the $13 \mathrm{~mm}$ line which can also provide density and temperature readings. More detail with regard to the experimental procedures and accuracies obtained is presented in Haldenwang (2003) and Haldenwang and Slatter (2006).

In Figure 2 a plot of wall shear stress versus bulk shear rate for a 6\% Kaolin slurry is presented. Such kaolin suspensions are model fluids which are able to portray rheological behaviour similar to a typical viscoplastic paste tailings material (Slatter, 2011). Each slope is presented separately. It is important to note that the laminar flow data is co-linear at the different channel slopes, as would customarily be seen for tube viscometer data plotted on a pseudo shear diagram, for different diameters. With tube viscometry data the transition and subsequent turbulent data can be observed. A similar phenomenon for the flume data is seen in Figure 2; here the transition and subsequent turbulent data can be clearly observed for the different channel slopes.

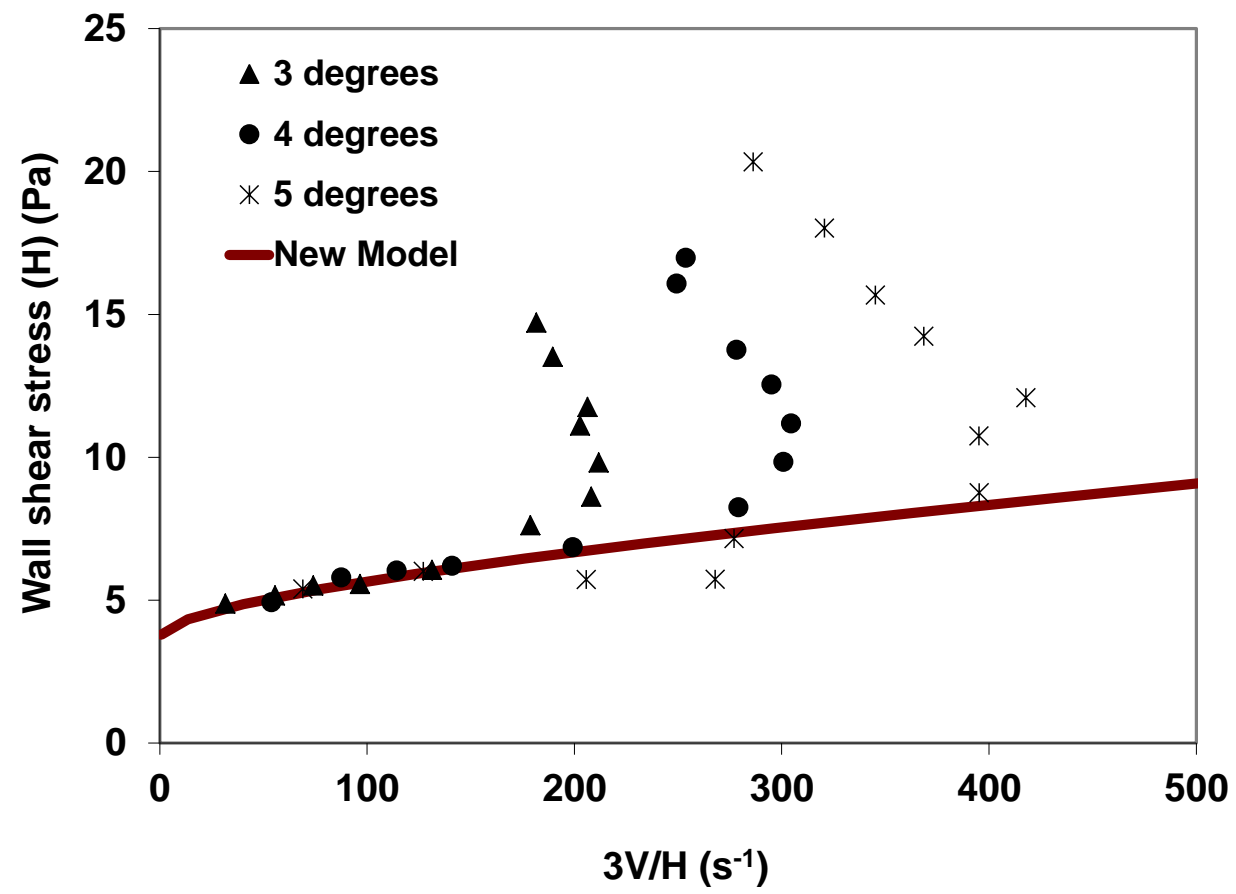

Figure 2 Plot of wall shear stress versus bulk shear rate for a $6 \%$ Kaolin slurry in a $300 \mathrm{~mm}$ rectangular channel

Since the primary objective of this paper is to establish a transitional flow criterion, the next task is to theoretically establish the actual transition values, and then ascertain whether these agree qualitatively and quantitatively with the experimentally observed transitions.

Figures 3 to 5 show the data for each channel slope against the predicted transition value calculated using the criterion $\mathrm{Re}_{4}=700$. 


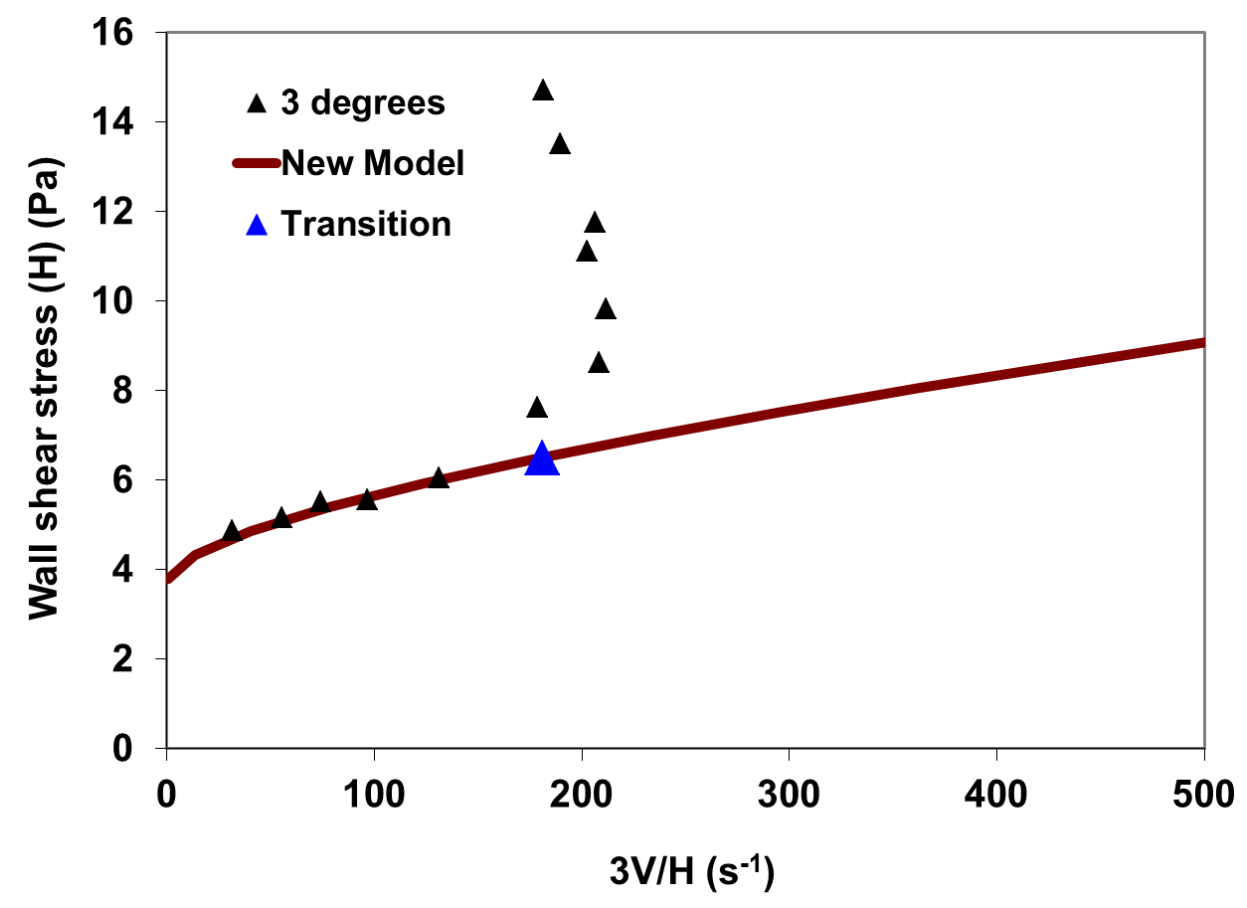

Figure 3 Plot of wall shear stress versus bulk shear rate for a $6 \%$ Kaolin slurry in a $300 \mathrm{~mm}$ rectangular channel at a slope of $3^{\circ}$, showing the theoretical transition point

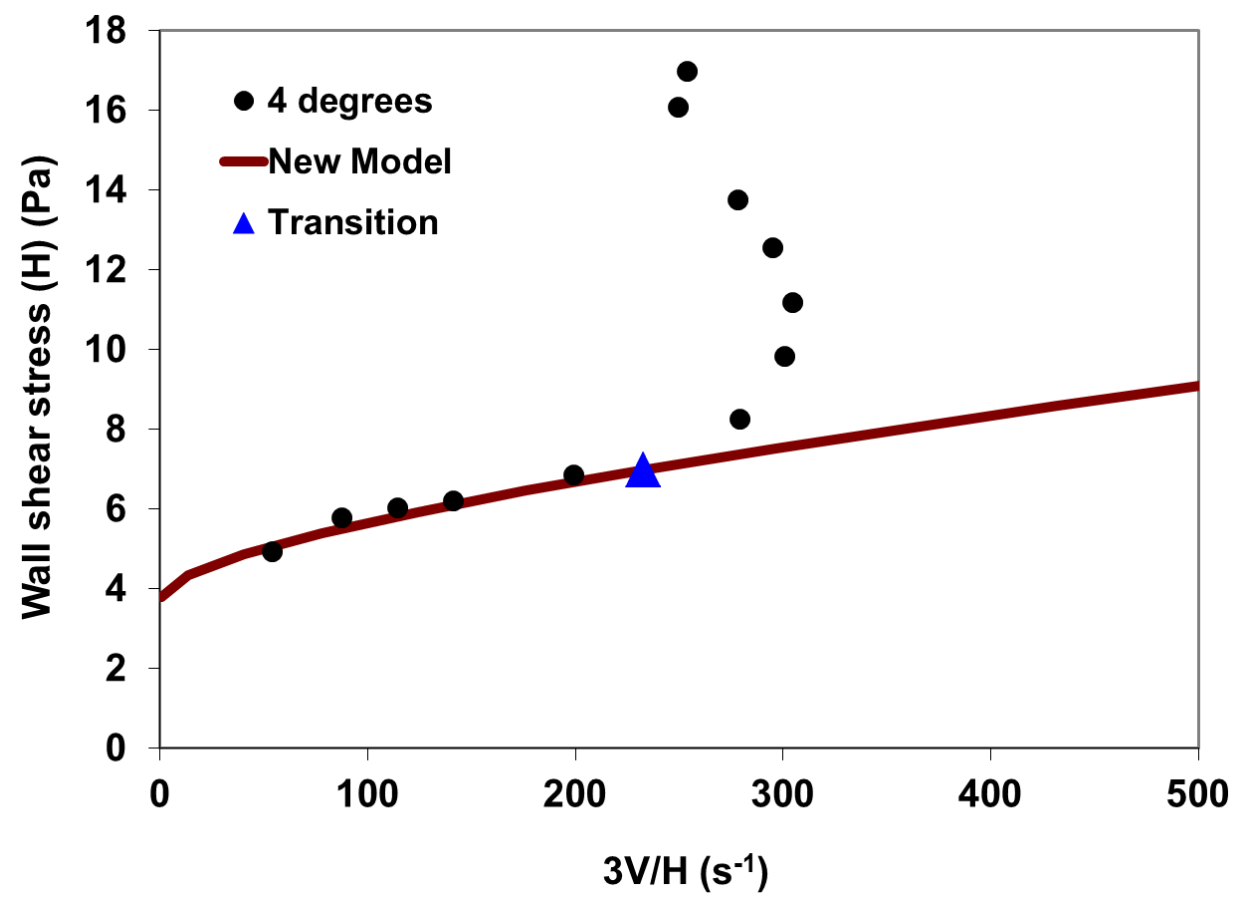

Figure 4 Plot of wall shear stress versus bulk shear rate for a $6 \%$ Kaolin slurry in a $300 \mathrm{~mm}$ rectangular channel at a slope of $4^{\circ}$, showing the theoretical transition point 


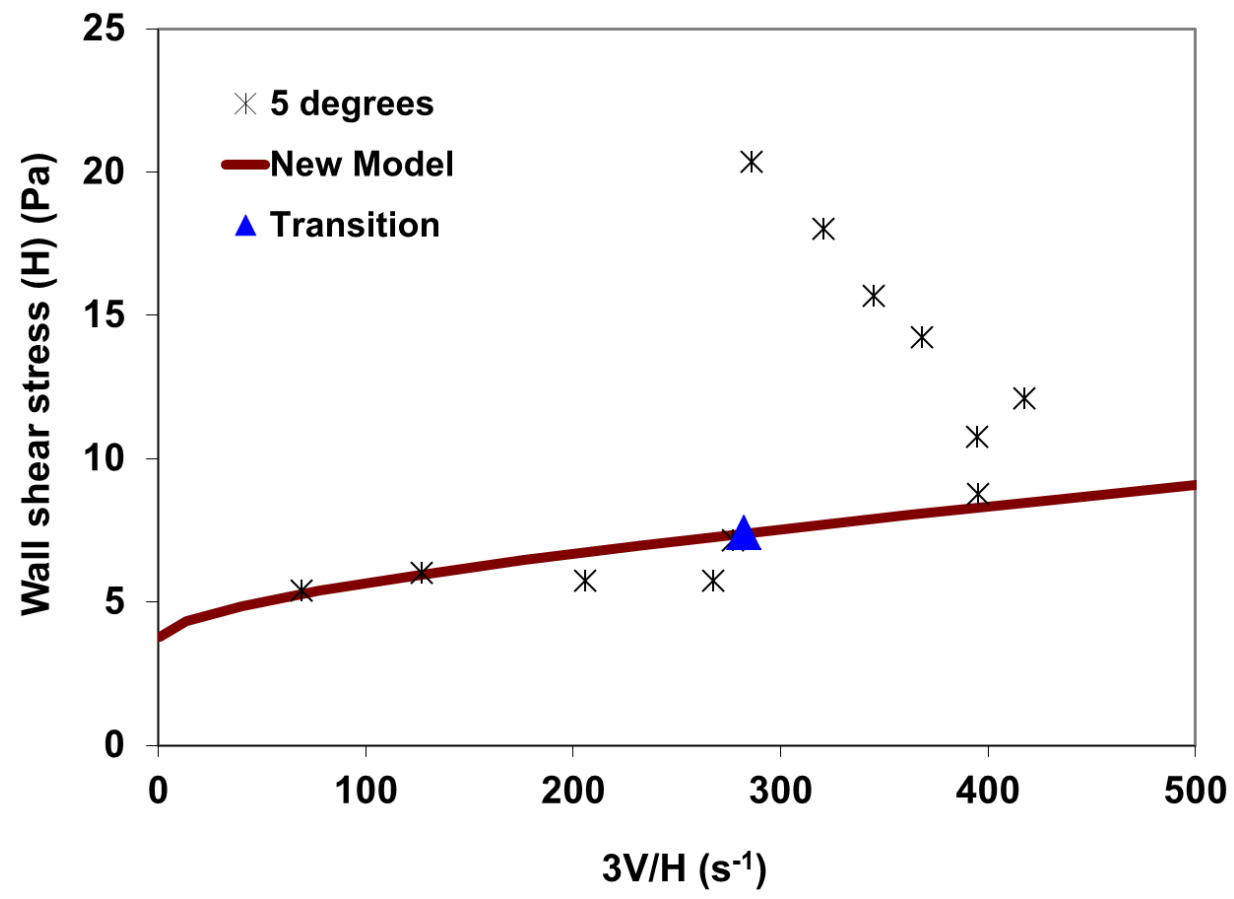

Figure 5 Plot of wall shear stress versus bulk shear rate for a $6 \%$ Kaolin slurry in a $300 \mathrm{~mm}$ rectangular channel at a slope of $5^{\circ}$, showing the theoretical transition point

Figures 3 to 5 show that there is generally good agreement between the transition predictions obtained using the criterion $\operatorname{Re}_{4}=700$, with more deviation at $5^{\circ}$. It should be noted that - as for critical pipe flow there may well be a zone or range of values within which transition can occur. However, a much larger and diverse data base would be required to delimit such a transition zone, and much further work is required.

\section{Discussion}

The principal objective of this paper - to extend the previous power law fluid work to a yield stress fluid has been achieved. Comparison with viscoplastic experimental data shows that the approach does have merit. A further benefit of the new approach is that laminar flume flow data can now be scaled up directly for engineering design purposes, provided that laminar flow is maintained. Alternatively, scale up can be performed via the sheet flow pseudo shear diagram, which can be constructed from the rheology as measured by standard bench-top methods. As is always of paramount importance in such work is the validity of such laminar flow scale up, which is critically dependent on the onset of turbulent flow which can now be predicted from the new transition criterion of $\mathrm{Re}_{4}=700$. The long established dogma - from Newtonian pipe flow - of a transition zone or range of values within which transition occurs, may well apply here. However, much further work over wide ranges of fluid and conduit properties would be required to delimit such a transition zone.

The phenomena of critical, tranquil or shooting flow, and how these can be related in non-Newtonian free surface flow, form the principal unresolved issues, which revolve around Froude number or free surface effects.

Extension of this approach to visco-plastic fluids has been made possible by using the tangent method at the relevant wall shear stress as proposed by Metzner and Reed (1955). This work has been validated using a small dataset, and further validation utilising a much more extensive dataset is needed. 


\section{Conclusions}

A previously developed analytical approach for the sheet flow of a power law fluid has been further developed and extended to accommodate viscoplastic paste material. This approach exploits the fact that the bulk shear rate is a unique function of the rheogram and the wall shear stress, and we have shown that this can be used for scale-up and design at any required slope and depth, in laminar flow. This approach, as well as the new criterion for the establishment of the onset of turbulent flow in sheet flow, has been validated using viscoplastic experimental data.

\section{Acknowledgement}

The support and encouragement of the ATC Williams team is gratefully acknowledged, without which this work would not have been possible.

\section{References}

Chow, V.T. (1959) Open channel hydraulics, McGraw-Hill Book Co., Singapore.

De Kee, D., Chhabra, R.P., Powley, M.B. and Roy, S. (1990) Flow of viscoplastic fluids on an inclined plane: Evaluation of yield stress, Chemical Engineering Communications, Vol. 96, pp. 229-239.

Haldenwang, R. (2003) Flow of non-Newtonian flow in open channels, unpublished D. Tech thesis, Cape Technikon, Cape Town, South Africa.

Haldenwang, R. and Slatter, P.T. (2006) Experimental procedure and database for non-Newtonian open channel flow, Journal of Hydraulic Research, Vol. 44, Issue 2, pp. 283-287.

Metzner, A.B. and Reed, J.C. (1955) Flow of non-Newtonian fluids - Correlation of the laminar, transition and turbulent flow regions, AlChE Journal, Vol. 1, No. 4.

Slatter, P.T., Haldenwang, R. and Chhabra, R.P. (2010) The sheet flow viscometer, Hydrotransport 18, in Proceedings 18th International Conference on the Hydraulic Transport of Solids, 22-24 September 2010, Rio de Janeiro, Brazil, BHR Group, Rio de Janeiro, pp. 299-307.

Slatter, P. Haldenwang, R. and Chhabra, R. (2011) The laminar/turbulent transition for paste sheet flow, in Proceedings 14th International Seminar on Paste and Thickened Tailings (Paste2011), R.J. Jewell and A.B. Fourie (eds), 5-7 April 2011, Perth, Australia, Australian Centre for Geomechanics, Perth, pp. 381-388.

Slatter, P.T. (2011) The engineering hydrodynamics of viscoplastic suspensions, in Particulate Science and Technology, Taylor \& Francis Inc., United States, Vol. 29, No. 2, pp. 139-150, ISSN: 0272-6351. 